\title{
1972 ELECTION RESULTS
}

The tellers for the 1972 election, Raymond F. Coughlin and Peter Hagis, Jr., have reported the election of the following members of the council and Board of Trustees. The terms in each case begin on January $1,1973$.

President: Saunders Mac Lane

Vice-President: Edwin E. Moise

Secretary: Everett Pitcher

Associate Secretaries: Walter H. Gottschalk, Orville G. Harrold, Jr.

Treasurer: W. T. Martin

Associate Treasurer: Murray H. Protter

Member of the Bulletin Editorial Committee: John L. Kelley

Member of the Proceedings Editorial Committee: Jacob Feldman

Member of the Colloquium Editorial Committee: Samuel Eilenberg

Member of the Mathematical Reviews Editorial Committee: Jacob T.

Schwartz

Member of the Mathematical Surveys Editorial Committee: Paul R.

Halmos

Committee to Monitor Problems in Communication: Duane W. Bailey, Allen L. Shields

Members-at-large of the Council, Anatole Beck, Michael Golomb,

Mary W. Gray, Arthur P. Mattuck, Cathleen S. Morawetz

Member of the Board of Trustees, Abraham H. Taub

Everett Pitcher, Secretary 